\title{
The Influence of Organizational Factors and Employee Engagement on the Performance of Doctors at the Haji Hospital in South Sulawesi Province and Dr. RSUP. Tadjuddin Chalid
}

\author{
Nurul Mutiah Aminuddin ${ }^{1}$, Syahrir A. Pasinringi ${ }^{1}$, Lalu Muhammad Saleh ${ }^{2}$ \\ Corresponding Email: nurul.mutiah@ymail.com \\ ${ }^{1}$ Department of Hospital Management, Faculty of Public Health, Hasanuddin University, \\ Indonesia \\ ${ }^{2}$ Department of Occupational Health and Safety, Faculty of Public Health, Hasanuddin \\ University, Indonesia \\ Received: May 15, 2021 \\ Received in Revised: July 14, 2021 \\ Accepted: July 26, 2021
}

\begin{abstract}
Performance represents behavior that is formally evaluated by the organization or company as part of the responsibilities and obligations of employees. This study aims to analyze the influence of organizational factors and employee engagement on the performance of doctors at the Haji Hospital in South Sulawesi Province and Dr. Tadjuddin Chalid. This type of research is a quantitative study using an observational study with a cross sectional study design. The samples in this study were doctors at the Haji Hospital in South Sulawesi Province and Dr. Tadjuddin Chalid, totaling 104 respondents. The results showed that there was a direct influence of Organizational Factors on the performance of doctors, a direct influence of Organizational Factors on Employee Engagement, a direct influence of Employee Engagement on the performance of doctors and there was an indirect influence of Organizational Factors on the Performance of Doctors through Employee Engagement at the Haji Hospital of South Sulawesi Province and Dr. Tadjuddin chalid. It is recommended to the hospital management to improve by holding regular general briefings to discuss and discuss matters related to the organization, the head of the room or installation to develop relationships between employees, respond more and provide support to their subordinates in order to create a good relationship between superiors and subordinates.
\end{abstract}

Keywords: Organizational Factors, Employee Engagement, Performance, Doctors, Hospitals

\section{Introduction}

Human resources have a very important role in an organization, both profit and non-profit organizations. Human resources are one of the factors that are directly involved in carrying out organizational activities and play an important role in increasing organizational productivity in achieving the goals that have been set. In a company, employees are the main asset who are active actors in every activity of the company. Employees have different feelings, thoughts, desires, status, educational background, age and gender which are brought into the organization.

Hospitals are considered as one of the organizations or health facilities that have an important role in improving the health status of the community. Hospital is a health service institution that provides complete individual health services that provide inpatient, outpatient, and emergency services. Therefore, hospitals are required to provide quality services which are largely determined by the human resources in it (Ministry of Health, 2009). 
Utilization of good human resources will help the organization in running the expected service system (Robbins \& Judge, 2008). As stated by Cazares (2011) that the organization's ability to achieve its goals depends on the willingness of employees to contribute. Houston (2006) further conducted research in the public sector where individual contributions would be beneficial in organizations. Therefore, human resources must be maintained and developed to be able to run an organization so that it becomes an effective organization and can achieve the goals of the organization.

One of the influential employee behavior in hospitals is the performance of doctors. Performance (job performance) is a behavior of employees who are involved in the work. Performance represents behavior that is formally evaluated by the organization or company as part of the responsibilities and obligations of employees (Sonnentag \& Frese, 2002). To achieve good performance, organizations must seek to improve employee performance as well as possible, because employee performance greatly affects the performance of the team or work group, and can affect the overall performance of the organization (Koopmans et al., 2011).

One of the factors that play an important role in the performance of an employee, is organizational factors which consist of indicators of Perceived Organizational Support, Service Climate and Authentic Leadership (Nandini, 2018). Organizational factors are related to the organization itself, in this case the organization requires thought, energy, skills and expertise contributed by workers, while employees depend on what is provided by the organization. This relationship can be viewed from the perspective of the work environment, supervision and consistency. Is the work environment in accordance with the needs of employees, whether the leadership can establish good communication with employees as well as regulations or policies regarding job descriptions and the payroll system. If these organizational factors are in accordance with what is expected by the company and employees, then the performance will be well formed (Steers \& Porter, 1982).

In addition to perceived organizational support and service climate, leadership in an organization is also very important in influencing employee performance, because leaders have a strategic role in achieving organizational goals which are usually stated in the vision and mission of the organization. The importance of aspects of human resources for the organization, then the role of a leader is no less important. Leaders function to move followers so that they want to follow or carry out what the leader commands and wants. Based on this opinion, it is concluded that leadership is one of the factors to improve performance.

One of the factors that also affect performance is employee engagement. Employee engagement needs to be established to create a sense of attachment between employees and the company. Employee engagement is a condition felt by employees where they consciously and faithfully give all of their energy, initiative, willingness to adapt, hard work, and persistence to achieve organizational goals (Macey et al, 2009). Research on employee engagement is very interesting to study because there is still not much research on employee engagement in the academic literature (Robinson et al in Saks, 2006). In fact, attention to employee engagement is still very little discussed in the world of human resources in Indonesia. This is followed by the lack of research on employee engagement in Indonesia. In Taneja (2015) it is stated that many studies have found a positive relationship between employee engagement and organizational performance outcomes, namely employee retention, productivity and profitability. This finding is supported by a 2012 Gallup study of 192 companies. It found that companies that rated high on employee engagement recognized higher profits $(22 \%)$, increased customer satisfaction $(10 \%)$, decreased theft $(28 \%)$, and fewer accidents at work (48\%).

RSUD Haji South Sulawesi Province and RSUP Dr. Tadjuddin Chalid is a government-owned class B hospital located in the city of Makassar. Class B hospitals are hospitals that are able to

Copyright $@$ 2021, Journal of Asian Multicultural Research for Medical and Health Science Study, Under the license CC BY-SA 4.0 
provide limited specialist and subspecialist medical services. This hospital was established in every provincial capital that accommodates referral services so that these two hospitals become referral hospitals for people from regencies/cities in the province of South Sulawesi. With this status, this hospital must be able to provide quality health services. To achieve this, hospitals are required to maximize all available resources to obtain maximum performance.

The results of the hospital performance evaluation were measured using the 2012 Minimum Service Standards (SPM). Of the 22 services measured, there were seven services that were directly related to the performance of doctors in measuring the indicators. Tadjuddin Chalid there are four of the seven MSS indicators (57.14\%) that have not been achieved according to the standard (100\%), namely Inpatient Services, Pharmacy Services and Medical Record Services.

Therefore, the researcher hopes to be able to carry out further analysis of the Organizational Factors and Employee Engagement variables on the performance of doctors so that hospitals are able to provide quality health services.

\section{Methods}

\section{Research Location and Design}

This research was conducted at the Haji Hospital of Sulawesi Province and at the Dr. Tadjuddin Chalid. The type of research used is a quantitative approach.

\section{Population and Sample}

The population of this study were all doctors who served and served in the Haji Hospital of South Sulawesi Province and Dr. Tadjuddin Chalid is 104 people. The sample size in this study was determined by a total sampling of 104 doctors.

\section{Method of Collecting Data}

The instrument used in data collection is a questionnaire, regarding the independent variables in the form of organizational factors and employee engagement, while the dependent variable is performance.

\section{Data Analysis}

Univariate analysis was conducted to obtain an overview of the research problem by describing each variable used in the study and the characteristics of the respondents. Univariate analysis consisted of descriptive analysis of respondents' characteristics and descriptive analysis of research variables. Bivariate analysis was carried out to see the relationship between two variables, namely between the independent variable and the dependent variable. The statistical test used was the chi square test. Multivariate analysis using path analysis

\section{Results and Discussion}

Table 1. Distribution of Respondents Based on the Characteristics of Doctors at the Haji Hospital in South Sulawesi Province and Dr. RSUP. Tadjuddin Chalid 2021

\begin{tabular}{|l|c|c|c|c|}
\hline \multirow{2}{*}{ Characteristic } & \multicolumn{2}{|c|}{ RSUD Haji } & \multicolumn{2}{c|}{$\begin{array}{c}\text { DSUP. Tadjuddin } \\
\text { Chalid }\end{array}$} \\
\cline { 2 - 5 } & $\mathrm{n}$ & $\%$ & $\mathrm{n}$ & $\%$ \\
\hline \multicolumn{3}{|c|}{ Age } & 7.8 \\
\hline 20-35 Years & 16 & 30.2 & 4 & 49.0 \\
\hline 35-45 Years & 23 & 43.4 & 25 & 43.1 \\
\hline$>$ 45 Years & 14 & 26.4 & 22 & \\
\hline
\end{tabular}




\begin{tabular}{|l|c|c|c|c|}
\hline \multirow{2}{*}{ Characteristic } & \multicolumn{2}{c|}{ RSUD Haji } & \multicolumn{2}{c|}{$\begin{array}{c}\text { RSUP Dr. Tadjuddin } \\
\text { Chalid }\end{array}$} \\
\cline { 2 - 5 } & $\mathrm{n}$ & $\%$ & $\mathrm{n}$ & $\%$ \\
\hline Total & 53 & 100.0 & 51 & 100.0 \\
\hline \multicolumn{5}{|c|}{ Sex } \\
\hline Male & 13 & 24.5 & 11 & 21.6 \\
\hline Female & 40 & 75.5 & 40 & 78.4 \\
\hline Total & 53 & 100.0 & 51 & 100.0 \\
\hline \multicolumn{5}{|c|}{ Years of Service } \\
\hline 3-5 Years & 7 & 24.5 & 6 & 11.8 \\
\hline 6-8 Years & 23 & 43.4 & 31 & 60.8 \\
\hline$>9$ Years & 23 & 43.4 & 14 & 27.5 \\
\hline Total & 53 & 100.0 & 51 & 100.0 \\
\hline \multicolumn{5}{|c|}{ Education } \\
\hline Public Doctor & 6 & 62.4 & 6 & 11.8 \\
\hline Specialist Doctor & 40 & 37.6 & 40 & 78.4 \\
\hline Dentist & 7 & 0.0 & 5 & 9.8 \\
\hline Total & 53 & 100.0 & 51 & 100.0 \\
\hline \multicolumn{5}{|c|}{ Employment status } \\
\hline PNS & 43 & 81.1 & 27 & 52.9 \\
\hline Other & 10 & 18.9 & 24 & 47.1 \\
\hline Total & 53 & 100.0 & 51 & 100.0 \\
\hline
\end{tabular}

Source: Primery Data, 2021

Table 1 shows the frequency distribution based on the characteristics of the sample at the study site, most of the respondents at the age level of 35-45 years, as many as 48 respondents $(46.2 \%)$. In terms of gender, most of the respondents were female, as many as 80 respondents $(79.6 \%)$. Based on years of service, most of the respondents worked for 6-8 years, namely 54 respondents (51.9\%). Judging from the latest education, most of the respondents were educated dr. specialists, as many as 80 respondents (76.9\%). And judging from the employment status, most of the others are civil servants as many as 70 respondents $(67.3 \%)$.

Table 2. Frequency Distribution of Doctor's Research Variables in 2021

\begin{tabular}{|l|c|c|}
\hline \multirow{2}{*}{ Variable } & R & Research Sample \\
\cline { 2 - 3 } & \multicolumn{2}{|c|}{ Organizational Factor } \\
\hline High & 46 & 44.2 \\
\hline Low & 58 & 55.8 \\
\hline Total & 104 & 100.0 \\
\hline \multicolumn{3}{|c|}{ Employee Engagement } \\
\hline High & 46 \\
\hline Low & 58 & 44.2 \\
\hline Total & 104 & 55.8 \\
\hline \multicolumn{3}{|c|}{ Performance } \\
\hline Good & 48 & 100.0 \\
\hline Less Good & 56 & 46.2 \\
\hline Total & 104 & 53.8 \\
\hline
\end{tabular}

Source: Primary Data, 2021 
Table 2 describes the percentage of respondents' assessment of the research variables. The results in most of the respondents stated that the category of Organizational Factor was low in the Haji Hospital and Dr. Tadjuddin Chalid with 55.8\%, in the category of low Employee Engagement at RSUD Haji and Dr. RSUP. Tadjuddin Chalid by $55.8 \%$, in the category of low performance at RSUD Haji and RSUP Dr. Tadjuddin Chalid by $53.8 \%$.

Table 3. Path Analysis Model of the Effect of Independent Variables on Dependent Variables

\begin{tabular}{|c|c|c|}
\hline Effect Between Variables & $\boldsymbol{p}$ & Estimate \\
\hline $\mathrm{X}_{1} \longrightarrow \mathrm{Y}_{1}$ & 0,000 & 3,603 \\
\hline Effect Between Variables & $\boldsymbol{p}$ & Estimate \\
\hline $\mathrm{X}_{1} \longrightarrow \mathrm{Y}_{2}$ & 0,000 & 4,141 \\
\hline Effect Between Variables & $\boldsymbol{p}$ & Estimate \\
\hline $\mathrm{Y}_{2} \longrightarrow \mathrm{Y}_{1}$ & 0,018 & 2,372 \\
\hline
\end{tabular}

Table 3 explains the effect of the independent variable on the dependent variable. The results showed that the influence of Organizational Factor (X1) on Performance (Y1), where from the statistical test results obtained the results of the p-value $(0.000)<0.05$, which means the p-value is less than the 0.05 significance level so that there is an influence of Organizational Factor on Performance. the effect of Organizational Factor (X1) on Employee Engagement (Y2), where from the statistical test results obtained from the p-value $(0.000)<0.05$, which means the $p$ value is less than the 0.05 significance level so that there is an Organizational Factor effect on Employee Engagement. the effect of Employee Engagement (Y2) on Performance (Y1), where from the results of statistical tests obtained the results of the p-value $(0.018)<0.05$, which means the p-value is less than the 0.05 level of significance so that there is an effect of Employee Engagement on Performance.

Research hypothesis 1 (H1) stated that organizational factors directly affect the performance of doctors. Based on the statistical analysis conducted, it is known that organizational factors directly affect the performance of doctors at the Haji Hospital, South Sulawesi Province and Dr. Tadjuddin Chalid. A significant effect is also shown by a significance value of 0.000 , so in this case research hypothesis 1 (H1) is accepted.

One of the factors that play an important role in the performance of an employee, is Organizational Factors which consists of indicators of Perceived Organizational Support, Service Climate and Authentic Leadership (Nandini, 2018). Organizational factors are related to the organization itself, in this case the organization requires thought, energy, skills and expertise contributed by workers, while employees depend on what is provided by the organization. This relationship can be viewed from the perspective of the work environment, supervision and consistency. Is the work environment in accordance with the needs of employees, whether the leadership can establish good communication with employees as well as regulations or policies regarding job descriptions and the payroll system. If these organizational factors are in accordance with what is expected by the company and employees, then the performance will be well formed (Steers \& Porter, 1982).

according to Rhoades \& Eisenberger (2002), perceived organizational support refers to employees' assessments of the extent to which the organization values their contributions and cares about their well-being. If employees perceive that the organizational support they receive is high, then the employee will integrate membership as a member of the organization into their identity and then develop a more positive relationship and assessment of the organization. By integrating membership in the organization with employee identity, the employee feels part of the organization and feels responsible for contributing and giving his best performance to his organization. 
The results obtained were $63.5 \%$ of doctors who stated that they did not agree with the statement "The hospital really considers my goals". on the statement "The hospital pays attention to me when I am successful in my job" by $68.3 \%$. on the statement "This hospital considers my opinion" by $66.3 \%$. on the statement "The hospital appreciates my contribution" by $61.5 \%$.

It can be seen that the perceived organizational support of the hospital is still lacking because there is still unfair treatment given by the hospital in appreciating the contribution of doctors in working in the hospital. The form of appreciation given by the organization to employees can be said to be fair if a feeling of fairness is felt by the employee towards all the income earned by the employee from the organization whose amount is proportional to the effort that the employee has done, and is comparable to the income received by other employees.

The results obtained were $66.3 \%$ of doctors who stated that they did not agree with the statement "The hospital pays attention to employees for good work and service". on the statement "The hospital provides training for knowledge and skills of employees in order to provide good service" amounted to $79.8 \%$. on the statement "Leaders support efforts to improve service quality" by $73.1 \%$. This is in line with the theory of Schneider (2004: 19) regarding service climate which states that if an organization has a strong climate for service, it will be seen from the existing policies, practices, and procedures reflecting that service is considered important in the organization.

According to Schneider (1998), service climate is an employee's perception of a set of policies, practices and procedures within the organization that support and reward behaviors that create quality service to customers. In line with this, according to Lytle, Hom \& Mowka, 1998 (in Tjiptono 2005: 103), a strong service climate is formed when employees agree that service quality is really focused on the organization and it is reflected in management behavior.

This statement is supported by research by Mahdian et al (2013) regarding the influence of Service Climate on performance and customer satisfaction. The results of the study stated that when employees feel motivated, encouraged and supported by the company, it will produce a high influence on employee performance, thus making them highly committed to the company and providing the best service to customers. Employee perceptions of company support related to the creation of service quality to customers is referred to as service climate.

The results obtained were $61.5 \%$ of doctors who stated that they did not agree with the statement "There is reciprocity from the leadership to increase interaction with their employees". on the statement "The leader said exactly what he meant" by $60.1 \%$. on the statement "The leader knows the ability of his employees" by $61.5 \%$.

In an organization or company, a very important leader role and responsibility are needed for the running of an organization or company. Companies can be said to have failed or succeeded in achieving their targets, which lies in the role of a leader. Some leadership theories emphasize the ability to carry out tasks and have the characteristics and expertise to solve problems that exist in the company. While other theories emphasize the ability that a person has in interacting with others such as the ability to influence those around him. Some other theories focus more on the personality that makes a quality leader (Andiyasari \& Pitaloka, 2010).

According to (Khan, 2010) authentic leadership is confident, hopeful, optimistic, tenacious, moral or ethical, future-oriented and prioritizes developing colleagues into leaders. True leaders are true to themselves and demonstrated behavior positively transforms or develops colleagues into leaders themselves. 
Research hypothesis 2(H2) states that organizational factors affect employee engagement. Based on the statistical analysis conducted, it is known that organizational factors affect employee engagement at the Haji Hospital, South Sulawesi Province and Dr. RSUP. Tadjuddin Chalid. A significant effect is also shown by a significance value of 0.000 , so in this case research hypothesis 1 (H1) is accepted.

Employee engagement is a person's mental state related to his work that is positive and full of character which is characterized by vigor, dedication and absorption (Schaufeli et al., 2002). Vigor characterized by high energy and mental resilience at work, the desire to invest in a job and persist despite adversity. Dedication refers to a person who is highly engaged in his work and feels significant, enthusiastic, inspired, proud, and challenged by his work. Absorption is characterized by being fully concentrated and happily engaged in one's work which causes time to pass quickly and the person finds it difficult to separate himself from his work.

From the results of research conducted, there are doctors who disagree with the statement "I am excited when I go to work" by $60.6 \%$. on the statement "I am enthusiastic in preparing an action plan or work given to me" by $67.3 \%$. on the statement "I am passionate about completing work on time" by $69.2 \%$.

It can be seen that doctors who work in hospitals have poor vigor values because more doctors feel normal when doing their jobs compared to doctors who have enthusiasm at work. It can also be seen that there are some doctors who are tired while doing their work. This can be influenced by the lack of rewards given to doctors, thus affecting the spirit of doctors at work.

The results of the study found that there were doctors who disagreed with the statement "come to work before working hours started" by $65.4 \%$. on the statement "I stay focused on working professionally and complete my responsibilities in my work if I get personal problems" by $60.6 \%$.

This shows that doctors who work in hospitals have poor vigor because more doctors come to work before working hours start compared to doctors who arrive late, even though there are doctors who come late but have understandable reasons such as the weather. erratic or due to traffic jams. It can be seen that doctors lack a high sense of responsibility towards their work so they try to come to work before work time starts. This can be influenced because of a sense of willingness and desire to try to the maximum in doing their work so that they are able to produce the best work.

Research hypothesis 3(H3) states that employee engagement has an effect on doctor's performance. Based on the statistical analysis conducted, it is known that employee engagement has an effect on the performance of doctors at the Haji Hospital in South Sulawesi Province and Dr. Tadjuddin Chalid. A significant effect is also shown by a significance value of 0.018 so that in this case research hypothesis $3(\mathrm{H} 3)$ is accepted.

Achieving goals is not only the duty of employees to be committed to making them happen through employee engagement. Companies also need to contribute, in this case is the HR. According to Hasibuan (2012), HRM is useful as the utilization, development, assessment, remuneration and management of individual members of the organization or work group. Furthermore, Schaufeli et al. (2002) defined it as a positive motivational state characterized by vigor, dedication, and absorption.

From the results of the research conducted, there were doctors who stated that they did not agree with the statement "I will help finish the work of my colleagues when my work is finished" by $52.9 \%$. on the statement "I feel happy when serving patients so that time seems to pass quickly" by $52.9 \%$. on the statement "I enjoy my job while serving patients" by $65.4 \%$. 
This shows that doctors who work in hospitals have poor absorption values because the results of this study indicate that doctors lack full attention to their formal work compared to doctors who directly want to help work outside their formal work. Absorption is one of the dimensions of employee engagement where at work is always full of concentration and serious about a job. At work time seems to pass so quickly and find it difficult to separate yourself from work. This can be influenced by the lack of a sense of responsibility that doctors have so they only want to concentrate fully on their work.

Absorption refers to concentrating fully and deeply, being immersed in work where time passes quickly and it is difficult to separate oneself from work, thus forgetting everything around them. People who score high on absorption usually feel happy to be distracted by work, feel immersed in work and have difficulty separating themselves from work. As a result, everything around them is forgotten and time seems to pass quickly. On the other hand, people with low absorption scores do not feel attracted and are not immersed in work, have no difficulty separating from work and they do not forget everything around them, including time (Schaufeli et al., 2002).

HRM also concerns the design and implementation of planning systems, personnel preparation, employee development, career management, job evaluation, employee compensation and good employee relations. All of these things are done by HR to realize positive employee performance that will benefit the organization and realize its goals.

From the results of the study, it was found that $61.5 \%$ stated that they did not agree with the doctor's statement which showed that patient care in conducting the initial assessment of the patient (initial assessment) which was carried out within 24 hours of the patient entering the hospital at the hospital was good. , but there are 81.7 which indicate that the patient care in conducting the initial assessment of the patient (initial assessment) which is carried out within 24 hours of the patient entering the hospital has been very good.

From the explanation above, it shows that the patient care provided by doctors at the hospital has been running well. This can be influenced by various aspects such as employee engagement that doctors have so that they have enthusiasm, willingness and perseverance in providing services to patients. It could also be because doctors have a sense of enthusiasm in their work and pride in their work so that they can provide good service to their patients.

Kahn(1990) mentions that engagement can lead to both individual outcomes (eg quality of work and one's work experience) and organizational outcomes (eg organizational growth and productivity). Other studies have also found that engagement has a relationship with positive aspects of job achievement (Lewiuci \&Mustamu, 2016). Employees who are engaged in their organization will do something even more than what the organization where they work for, have less sickness, increase their productivity, and have a high commitment to the organization (Schaufeli et al., 2002)

The results showed that in patient care in educating doctors to patients, $81.7 \%$ of doctors felt that they were good at educating patients in hospitals. There are $18.3 \%$ doctors who think they are very good in providing education to patients.

This explains that the performance of doctors working in hospitals has done quite good patient care. This can be seen because doctors have a high sense of responsibility so they pay more attention to their patients by doing patience care. This can be influenced because doctors have a sense of pleasure in providing services to patients so that they want to take the time to provide education to their patients. This can also be influenced by the individual aspects of a person where the doctor has good abilities and skills, so that he can provide the best for patients. 
The results showed that there were $34.6 \%$ of doctors who in patient care respect the rights of patients and families stating it is good, there are also $41.8 \%$ doctors who think that they lack in respecting the rights of patients and families, and there are also doctors who stated that he was very good at respecting patient rights, which was $17.3 \%$. This shows that the performance of doctors who work in hospitals is good in carrying out patient care in respecting the rights of patients and families. A good doctor's performance can be influenced by various factors such as a good relationship with the organization and a doctor's enthusiasm and pride in serving patients so that he can respect the rights of patients and their families in order to provide the best service for their patients.

From the results of the study showed that there were $26 \%$ of doctors who stated that they were good in medical/clinical knowledge by always updating Always updating the ability to establish diagnosis and patient management by attending training for at least 20 hours per year, there were also doctors who stated that they were very good in medical/clinical knowledge by always updating. Always updating the ability to establish diagnosis and patient management by attending training for at least 20 hours per year by $19.2 \%$, but there were also $54.8 \%$ a doctor who states that he is still not good in medical/clinical knowledge by always updating. Always updating his ability to establish a diagnosis and management of patients by attending training for at least 20 hours per year.

This shows that the performance of doctors working in General Hospitals is good because they always try to update their ability to diagnose and treat patients by attending training for at least 20 hours per year. This can be influenced because the doctor has good abilities and skills and it can also be because he always feels happy in providing services to patients, so doctors always try to increase their knowledge that can be applied when dealing with patients.

The competence of doctors in patient care and prevention of malpractice depends on several factors which are not only limited to personal characteristics (age, gender) but also professionalism through updating knowledge through participation in education/training, so that competence in medical science is increasing in patient care services (Wenghofer et al., 2009).

The results showed that there were $61.5 \%$ of doctors who stated that they were good at using scientific methods and medical language for patient evaluation, the use of appropriate abbreviations in writing diagnosis and therapy, and there were also doctors who stated that they were very good at using scientific methods and medical language for patient evaluation, the use of appropriate abbreviations in writing diagnosis and therapy which is $19.2 \%$, but there are also 19.2 percent who are not good at using scientific methods and medical language for patient evaluation, the use of abbreviations appropriate for writing diagnosis and therapy.

With the explanation above, we can conclude that the performance of doctors working in hospitals has been good because many doctors have used scientific methods and medical language for patient evaluation, using appropriate abbreviations in writing diagnoses and therapy. This can be influenced because of the individual aspects of the doctor, namely he has the ability and skill in using scientific methods and medical language for patient evaluation, the use of appropriate abbreviations in writing diagnoses and therapy so that this can be used as scientific evidence and improve patient care practices. . This can also be due to the doctor's pride in providing services to patients so that he wants to provide the best for patients.

The results of the study showed that there were $71.2 \%$ of doctors who were good at communicating with patients and their families, there were complaints from patients or patients' families for the services provided, and there were also $28.8 \%$ of doctors who felt very good in doing this. the patient and the patient's family, the existence of complaints from the

Copyright $\odot 2021$, Journal of Asian Multicultural Research for Medical and Health Science Study, Under the license CC BY-SA 4.0 
patient or the patient's family for the services provided.

From the statement above, it can be said that the performance of doctors who work in hospitals is good, because many doctors feel they are good in communicating with patients and their families, there are complaints from patients or patients' families for the services provided. This can be influenced by the establishment of a good relationship between the organization/supervisor, co-workers and the patient or the patient's family with the doctor so that the doctor is able to establish good communication. This can also be influenced by the doctor's persistence in establishing relationships/communication. As we know that with good communication can lead to good relationships too.

Good communication skills or social skills provide more advantages in human life between humans. Those with high levels of abilities and skills are useful for dealing with stress or anxiety more easily and for adapting and adjusting to life better and being less likely to suffer from depression, loneliness or anxiety. In the context of communication, it is important for a health professional to have good communication skills (Rogers, 1996).

From the results of the study, it was found that there were about $66.3 \%$ of doctors who stated that they were good at communicating with colleagues/nurses, there were complaints from colleagues/nurses/staff in patient service work relationships, as for $33.7 \%$ doctors who considers that he is very good at communicating with colleagues/nurses. This shows that the performance of doctors working in hospitals is good, because many doctors feel they are good, because doctors are able to communicate with colleagues/nurses, there are complaints from colleagues/nurses/staff in a good patient service relationship. . This can be influenced by the doctor's enthusiasm and willingness to communicate well with colleagues/nurses, complaints from colleagues/nurses/staff in patient care work relationships.

The results obtained were $36.5 \%$ of doctors who stated that they were good at understanding the laws and regulations regarding health services, including filling out a medical resume that was clearly legible, complete, and timely with the name, signature, date and time clearly obtained. As a result, there are also doctors who feel very good in understanding the laws and regulations regarding health services, including filling out a medical resume that is clearly legible, complete, and on time accompanied by a clear name, signature, date and time. $20.2 \%$, and there are no doctors who do not understand the laws and regulations on health services, including filling out a medical resume that is clearly legible, complete, and on time accompanied by name, signature, date and time that clearly results are obtained.

From the explanation above, it can be concluded that the performance of doctors working in hospitals is good, because there are no doctors who do not understand the laws and regulations regarding health services, including filling out medical resumes that are clearly legible, complete, and on time accompanied by name, signature. , date and time clearly obtained results. This can be influenced by the doctor's enthusiasm and pride so that he does not want to make mistakes in filling out his patient's medical resume. It is very important to fill in the medical record properly because it concerns the patient's health condition, so that the doctor should not be wrong in filling out the patient's medical resume.

Recording data and medical records of patients' health is important in the medical world known as medical record data. The patient's medical record data can be used as a reference for subsequent patient health checks, as well as recorded evidence regarding the patient's disease diagnosis and medical services obtained by the patient. Completeness of medical records is very useful for knowing in detail the patient's medical history, examination actions that have been carried out, and planning further actions. The diagnosis of a disease determined by a doctor, will greatly affect the actions of the patient both in treatment or even the action to be

Copyright (O) 2021, Journal of Asian Multicultural Research for Medical and Health Science Study, Under the license CC BY-SA 4.0 
taken. An accurate diagnosis is based on anamnesis, physical examination data, supporting examinations and written or information from a good and complete medical record in the medical record file (Benaloh, Chase, Horvitz, \& Lauter, 2009)

From the results of the study, there were $32.7 \%$ of doctors who stated that they were good in complying with policies and service procedures at the hospital, while doctors who felt they were very good in complying with hospital policies and procedures were $16.3 \%$, but there were also doctors who feel that they are still not good at complying with the policies and procedures of hospital servants whose value is $51 \%$. This shows that the performance of doctors working in General Hospitals is good, because there are many doctors who are good at complying with hospital policies and procedures. This can be influenced by the doctor's sense of responsibility, so that he does not want to violate the applicable regulations in the hospital. This can also be caused by a good relationship between superiors and colleagues so that they do not want to violate applicable regulations.

Factors that affect compliance based on Milgram's (1963) theory in Sarwono (1993) and Myers (2014) include location status, personal responsibility, peer support, legitimacy of authority figures, status of authority figures, and closeness of authority figures. The closeness of authority figures is one of the factors that affect compliance. In Milgram's experiment, when an authority figure left the room and gave his instructions over the phone, obedience decreased. On the other hand, when the authority figure is close, compliance will tend to be higher. With the presence of an authority figure, they can supervise directly and provide direct instructions regarding procedures and also directions on what to do.

The results of the study showed that there were $63.5 \%$ of doctors who stated that they were good at having a commitment to continuously developing professionalism, and attending medical team meetings, there were also doctors who felt that they were very good at having a commitment to continue to develop professionalism, and attend medical team meetings by $15.4 \%$, but there are $21.2 \%$ doctors who feel they are still not good at being committed to continuously developing professionalism, and attending medical team meetings .

From the statement above, it shows that the performance of doctors who work in General Hospitals is quite good, because quite a lot of doctors have a commitment to continuously develop professionalism, and attend medical time meetings. In this case, there are some doctors who still feel that they lack commitment to continuously develop professionalism, and attend medical time meetings, there are several factors that can influence doctors to be good at having a commitment to continuously developing professionalism, and attending in medical team meetings, such as support and motivation from superiors and colleagues. There are also factors that affect doctors who are already good at having commitments, such as a sense of willingness and perseverance of doctors to apply professionalism, practice of medical ethics, understanding, and sensitivity to population diversity as well as an attitude of responsibility towards patients, the medical profession, and society.

From the results of the study, it was found that there were $43.3 \%$ of doctors who felt they were good at having a commitment to continuously develop ethical practices including carrying out health services every day, during working hours, there were also doctors who felt very good in having health services. commitment to continuously develop ethical practices including carrying out health services every day, during working hours, but there are also doctors who are still not good at having a commitment to continuously developing ethical practices including carrying out health services every day, during working hours the value is $14.4 \%$ and there are also doctors who feel that they are still not very good at being committed to continuously developing ethical practices including carrying out health services every day, during working hours, which is $42,4 \%$. 
From the explanation above, it can be seen that the performance of doctors who work in General Hospitals is good, because many doctors have a professional attitude with a commitment to continuously develop ethical practices including carrying out health services every day, during working hours. This can be influenced by the doctor's sense of responsibility so that he always wants to develop ethical practices in carrying out health services. The spirit and perseverance of the doctor can also influence this, because he will always try to provide the best service for his patients. Caesens \& Stinglhamber (2014) stated that high levels of engagement lead to positive outcomes for the individual (the quality of people's work and their experience in doing the work) as well as the organizational level (organizational growth and productivity).

In the variable the doctor's performance can be said to be good, this can be influenced because of the doctor's enthusiasm and pride in his work so that he is always willing to try to provide the best service for patients. This research is in line with research by Yongxing et al., (2017) on customer service employees at telecommunications companies in South China, shows that work engagement has a significant effect on employee performance, with the results showing $=0.12, \mathrm{p}<0.01$. Research conducted by Bakker \& Bal (2010) shows the results of the significant effect of work engagement on the performance of teachers in elementary schools in the Netherlands, the results show the results of $\gamma=0,424 ; p<0,001$. Employees will feel interested in the success of the company and are motivated to improve performance to a level that exceeds job requirements, so it is considered as something that can bring change to individuals, teams, and companies (Bakker et al., 2014).

Research hypothesis 4 (H4) states that organizational factors affect the performance of doctors through employee engagement. Based on the results of the calculations, it is known that organizational factors affect the performance of doctors through work engagement. Based on the results of the calculations carried out, it is shown that the direct coefficient value is smaller than the indirect coefficient value, namely 0.018 . So in this case research hypothesis $4(\mathrm{H} 4)$ is accepted.

Based on the analysis carried out, organizational factors directly affect the performance of doctors at Haji Hospital, and Dr. RSUP. Tadjuddin Chalid. This means that without work engagement, organizational factors can directly affect the performance of doctors. This is supported by research Afzali, Motahari, \& Shirkouhi (2014) where the results of the study indicate that organizational support variables have an influence on employee performance. Positive support from the organization makes employees have a good perception and consider themselves obliged to repay the organization with something good too, one of which is through optimal performance, so as to create mutually beneficial relationships

\section{Conclusion}

The results showed that there was a direct influence of Organizational Factors on the performance of doctors, a direct influence of Organizational Factors on Employee Engagement, a direct influence of Employee Engagement on the performance of doctors and there was an indirect effect of Organizational Factors on the Performance of Doctors through Employee Engagement at Haji Hospital, South Sulawesi Province and Dr. Tadjuddin chalid. It is recommended to the hospital management to improve by holding regular general briefings to discuss and discuss matters related to the organization, the head of the room or installation to develop relationships between employees, respond more and provide support to their subordinates in order to create a good relationship between superiors and subordinates.

\section{References}

Andiyasari, A., \& Pitaloka, A. (2010). Persepsi kepemimpinan otentik dan work engagement 
pada generasi x \& y di indonesia. Jurnal Universitas Paramadina, 7(1), 371-388.

Bakker, A. B., \& Bal, P. M. (2010). Weekly work engagement and performance: A study among starting teachers. Journal of Occupational and Organizational Psychology, 83(1), 189-206.

Bakker, A. B., \& Demerouti, E. (2008). Towards a model of work engagement, 13(3), 209223.

Bakker, A. B., Demerouti, E., \& Sanz-Vergel, A. I. (2014). Burnout and work engagement: The JD-R approach. Annu. Rev. Organ. Psychol. Organ. Behav., 1(1), 389-411.

Houston, D. J. (2006). "Walking the walk" of Public Service Motivation: Public Employees and Charitable Gifts of Time, Blood, and Money. Journal of Public Administration Research and Theory, 16(1), 67-86.

Kahn, W. A. (1990). Psychological Conditions of Personal Engagement and Disengagement At Work. Academy of Management Journal, 33(4), 692-724.

Macey, William H. (2009). Employee Engagement: Tools for Analysis, practice, and Competitive Advantage. United Kingdom: Black- Willey.

Nandini, Borah. (2018). Eployee Engagement: A Critical Review of Literature. Journal of organization \& Human Behaviour, 7(4):22-30.

Organ, D. W. (1988). Organizational Citizenship Behavior: The Good Soldier Syndrome. Lexington: Lexongton Books.

Organ, D. W., \& Ryan, K. (1995). A Meta-Analitic Review of Attitudinal and Dispositional Predictos of Organizational Citizenship Behavior. Personnel Psychology.

Organ, D. W., Podsakoff, P. M., \& MacKenzie, S. B. (2006). Organizational Citizenship Behavior: Its Nature, Antecedents, and Consequences. USA: SAGE Publication, Inc.

Robbins, S. P., \& Judge, T. A. (2008). Perilaku Organisasi (Kedua Bela). Jakarta: Salemba Empat.

Saks, A. M. (2006). Antecedents and consequences of employee engagement. Journal of Managerial Psychology, 21(7), 600-619.

Schaufeli, W.B., Bakker, A.B. (2003). UWES -Utrecht Work Engagement Scale: Test Manual. Unpublished. Department of Psychology. Urecht University

Steers, R. M dan Porter, L. W. (1982). Motivation and Work Behavior 3rd edition. United State: Mc Graw Hill.

Taneja, Sonia (2015). A Culture of Employee Engagement: A Strategic Perspective for Global Managers. International Journal of Business Strategy, 36(3), 46-56. 